\title{
MIRADA Y MEMORIA EN LA MINIFICCIÓN DE JULIA OTXOA. LA EXTRAÑEZA AL SERVICIO DEL COMPROMISO ${ }^{1}$
}

\author{
GAZE AND MEMORY IN THE FLASH FICTION OF JULIA OTXOA. \\ STRANGENESS AT THE SERVICE OF ENGAGEMENT
}

\author{
Raquel VELÁZQUEZ VELÁZQUEZ \\ Universitat de Barcelona \\ raquel_velazquez@ub.edu
}

\begin{abstract}
Resumen: El objetivo de este artículo es identificar los pilares que sustentan la minificción de Julia Otxoa y esclarecer sus claves interpretativas. Se reconocen la mirada y la memoria como los cimientos esenciales de su producción; se estudian las conexiones entre lo insólito (en concreto lo distópico) y el espíritu ético que vertebra su obra; y se analizan los procedimientos formales más habituales. Aunque se toma como corpus principal el volumen de minificción Confesiones de una mosca (2018), no se soslayan los oportunos enlaces con todo el entramado global que constituye la obra de Julia Otxoa.
\end{abstract}

Palabras clave: Julia Otxoa. Minificción. Compromiso social. Insólito. Distopía.

Abstract: The aim of this article is to identify the pillars that support Julia Otxoa's microfiction and to clarify its interpretative keys. Gaze and memory are recognized as the essential foundations of her production; the connections between the unusual (specifically the dystopian) and the ethical spirit in her work are studied; and the most common formal procedures are analyzed. Although the volume of the microfiction Confesiones de una mosca [Confessions of a fly] (2018) is taken as the main corpus, we do not overlook the relevant links with the rest of Julia Otxoa's work.

Keywords: Julia Otxoa. Flash Fiction. Social Engagement. Unusual. Dystopia.

\section{APERTURA}

Cómoda en los géneros breves, Julia Otxoa llega a la minificción desde la poesía, como un encuentro inesperado que le sale al paso en el momento en que su mensaje necesita de un continente con distintas propiedades:

\footnotetext{
${ }^{1}$ El artículo es resultado del proyecto de investigación Lo fantástico en la cultura española contemporánea (1955-2017): narrativa, teatro, cine, televisión, cómic y radio, del Ministerio de Economía, Industria y Competitividad (FFI2017-84402-P, I.P. Dr. David Roas).
} 
Un buen día descubrí que el poema iba transformándose en otro paisaje en el que aparecían figuras, voces que tenían historias que contar, y el resultado final fue que el poema dio paso a la narración, pero sin abandonar aquellas herramientas de concisión y brevedad propias de las imágenes poéticas (Otxoa, 2006: 11).

Estos restos propios del lenguaje poético que traslucen sus textos narrativos no son los únicos que se cuelan en su minificción. Las disciplinas artísticas que cultiva Julia Otxoa (poesía, narrativa breve, poesía visual, fotografía, artes plásticas) están en permanente interconexión, y los trasvases suceden de forma continua en todas direcciones. Por otro lado, lo insólito en sus distintas modalidades (lo maravilloso, lo fantástico, lo distópico, lo absurdo), así como la exploración formal, se ponen al servicio de una literatura fundamentalmente de compromiso, de denuncia. Julia Otxoa es la mujer escritora que dice no, como el protagonista de El hombre rebelde, de Albert Camus, uno de sus libros de cabecera. La rebeldía de Julia Otxoa encuentra un cauce en su obra literaria y artística, que se construye desde el compromiso ético con la realidad circundante (pasada y presente). Su mirada sobre el mundo le descubre barbarie, horror, injusticia, y la única vía que se abre como posible para plasmar el objeto y sujeto de su mirada es la perplejidad y la extrañeza.

Partiendo de estas evidencias generales, este artículo nace de la intención de identificar los pilares que sustentan la obra minificcional de Julia Otxoa, y de esclarecer sus claves interpretativas. En él se estudia la relación entre lo insólito (y en concreto lo distópico) y el espíritu crítico que impulsa la obra de la autora, se determinan los espacios fronterizos en los que se acomoda su producción, y se analizan los distintos procedimientos formales que se ponen en práctica.

Para ejemplificar todo ello, este trabajo focaliza su atención en el que hasta el año 2021 (están en marcha varios proyectos en torno a la memoria familiar/memoria histórica) es su último volumen publicado: Confesiones de una mosca (2018). Debido al carácter integral de su obra, sin embargo, no sorteamos los necesarios enlaces con el resto de la producción de Julia Otxoa, en todos sus géneros y modalidades.

\section{LA PRODUCCIÓN DE JULIA OTXOA COMO ENTRAMADO INTEGRAL}

Las variadas disciplinas artísticas que cultiva Julia Otxoa es la urdimbre con la que se va tejiendo su obra. Son hilos que pertenecen al mismo telar, por lo que las distintas telas que salen de él tienen un sostén común. Un estudio de cualquiera de esas telas quedaría, por tanto, incompleto sin tener en cuenta todo el entramado global.

Este consistente tejido que revela su obra —un árbol con diferentes ramas, según metáfora de la propia autora - se pone de manifiesto en multitud de singularidades. Algunas de ellas, de carácter más externo, afectan a la comunicación que se propicia entre los textos. Varios de sus volúmenes se componen con la inclusión, además de los inéditos, 
de algunos textos publicados con anterioridad, lo que transmite el enfoque de producción abierta. A esta idea contribuye también la perspectiva intermedial, que propone la dialéctica entre palabra e imagen. En lo que podríamos denominar un proceso de postproducción, Julia Otxoa vuelve sobre sus textos ya publicados y los amplía con nuevos sentidos gracias al acompañamiento de imágenes de su propia autoría, que publica en el entorno hipermedial de su red social Facebook. Nuevos sentidos (visuales, metafóricos) se suman, entonces, a ese primer texto textual, lo que amplía los mapas de significados de sus microficciones. "Como todas las noches" (22/06/2020), "Mujeres imantadas" (05/07/2020), "Discurso" (28/07/2020), o "El notario de los nuevos tiempos" (28/10/2020), todos ellos pertenecientes al volumen Confesiones de una mosca (2018), son algunos de los textos que volvemos a encontrar en su red social, en este caso dos años después de haber visto la luz en la editorial Menoscuarto. La obra gráfica, los collages fotográficos que se asocian a los microrrelatos enriquecen la significación y exigen una nueva lectura del texto a la luz de la imagen, y viceversa.

Ya en el seno del texto, las marcas que constatan la voluntad de aludir a las raíces de un mismo árbol son múltiples. Junto a las más obvias, como la reincidencia en unos mismos temas nacidos del compromiso ético de la autora (la violencia, la injusticia, la insolidaridad, las consecuencias de las crisis económicas, etc.), o el uso de unas mismas aproximaciones (fantástica, distópica, esperpéntica, absurda, grotesca), hallamos la insistencia en unos idénticos motivos o referencias. Así, tanto en sus textos narrativos como poéticos Julia Otxoa recupera el simbolismo del enterrador, de las cabezas decapitadas, de la mosca conectada a la muerte; o referencias como la recurrida Avda. de la Libertad (usada, en ocasiones, como paradoja de la falta de ella). Algunos títulos que comparten su obra gráfica y su narrativa, o los repetidos homenajes en varios soportes a su abuelo Balbino, asesinado en 1936, se suman a este efecto de continuum.

Por último, aun con carácter anecdótico, cabe mencionar la reconversión de un mínimo fragmento dependiente de un texto más amplio en un relato con total autonomía. Es el caso de "Escritura", donde la entrevista al embajador de Esmeraldina sobre la medida gubernamental de colocar leones en la frontera para frenar la inmigración es solo la brevísima historia que ha aparecido de forma insospechada sobre la mesa de la protagonista. Julia Otxoa se da cuenta de las posibilidades de este fragmento-microrrelato que había incluido en el volumen de 2013 Escena de familia con fantasma y lo desarrolla hasta que se convierte, años más tarde, en "Cita en la embajada", de Confesiones de una mosca (2018).

Descreída de las divisiones y fronteras entre los géneros, cuando la autora elige, buscando la narratividad, la forma breve del microrrelato, siguen interactuando y calando en la escritura, asimismo, sus otras disciplinas artísticas. En "Todo empezó en un viejo armario", el texto que antepuso a Un extraño envío, y que puede ser entendido como una informal poética personal del microrrelato, defendía: "Lo sugerido, lo entrevisto, es tan esencial en mis textos como aquello específicamente narrado en ellos" (Otxoa, 2006: 11). El análisis de su minificción nos permite matizar que, en ocasiones, lo sugerido es incluso 
más esencial que lo narrado. En numerosos relatos, su autora rebaja la dosis de narratividad al mínimo, y sobresale por el contrario la estampa, la impresión, tan evidente en la poesía visual.

Julia Otxoa siempre ha defendido lo innegable de la continua interrelación de las distintas artes en su proceso creador, y de las huellas que de esta quedaban en su escritura. Su obra es el resultado de la convergencia de distintos lenguajes:

Vengo del mundo de la poesía, sigo escribiendo poesía, hay en toda mi obra narrativa una gran carga simbólica, alegórica, que encuentro imprescindible para la expresión de cuanto quiero narrar. Lo poético, lo simbólico, está muy ligado a la imagen, es algo fundamental, algo así como su cimiento y, en mi caso, la estructura sobre la que se construye el relato. [...] como artista plástica, todo lo referente a lo visual tiene una gran influencia en mi obra, junto con lo simbólico y poético (Otxoa en Enamorado, 2014: 11).

Por otra parte, la historia contenida en cada microrrelato suele ser producto de haber realizado un corte en una línea espacio-temporal, como si se tratara de un mínimo tranche de vie que, sin embargo, rehúye de la representación más puramente realista. Estos pedazos de vida, en que se presta más atención a las sensaciones que provocan que a las acciones que tienen lugar en ellos, tienden a la presentación de una trama diluida, y a un final que es percibido, más que como desenlace, como disolución.

Todos estos ingredientes en confluencia, fruto de la deliberada interrelación con otras artes, y de la apuesta de su autora por el hibridismo genérico promueven una minificción caracterizada muchas veces por la indeterminación. En esos casos, las posibilidades interpretativas son tantas que el lector — sin todas las pistas - queda con más preguntas que respuestas. La autora le obliga a detenerse tras la lectura, le deja suspendido en el aire de la interpretación, no para que descifre aquello que no necesariamente espera ser descifrado, sino para que se sumerja en el texto, se formule más preguntas, y adopte una postura crítica y reflexiva ante lo presentado. La inconfundible voz de Julia Otxoa entre los escritores y escritoras de minificción del presente siglo se debe en parte al cultivo de estos microrrelatos en suspensión, idiosincrásicos de su narrativa breve.

De la indeterminación y la disolución de la trama, así como de la constante búsqueda del sentido por parte del lector, se ocupó la escritora en su microrrelato metaficcional "Corrientes literarias" (Confesiones de una mosca), cuando se refería con un sintagma acertadísimo a las "narraciones sin asidero" (Otxoa, 2018: 34). La ficcionalidad del texto, y el humor habitual con el que aborda la reflexión metaliteraria, no debe distraernos del alcance de algunas de las consideraciones planteadas, que pueden ser percibidas como alusiones a la propia búsqueda de la autora, y por tanto ser leídas como claves de su poética.

El microrrelato lo constituye la respuesta, sirviéndose del género epistolar, de Apólocrates a Hiparco, quien haciéndose eco de los debates en las tertulias literarias de la ciudad le ha mostrado previamente al primero su curiosidad por el significado de ese 
tipo de narración que "se bambolea en el vacío, aparentemente sostenido por un precario andamiaje que hunde sus cimientos en un pozo de niebla" (Otxoa, 2018: 34).

Aunque en la carta de Apolócrates estas narraciones no salen bien paradas, subyace, de modo implícito, la defensa de la flexibilidad del género, desde un acercamiento paródico por parte de la autora. La dureza de Apolócrates hacia estos relatos donde el argumento queda diluido se agrava cuando se detiene en los lectores que se muestran atraídos por ellas en su desesperada búsqueda del sentido. El final de esos perseguidores muestra lo poco recomendable de ese viaje: "Que imprudentes lectores hayan perecido en ese intento de búsqueda de argumento, no es de nuestra incumbencia ni responsabilidad" (Otxoa, 2018: 35).

\section{MIRADA Y MEMORIA. LA ARTISTA "COSIDA A SU TIEMPO"}

La cimentación sobre la que se va edificando la producción de Julia Otxoa está constituida por dos bases esenciales: la mirada y la memoria.

La mirada de la autora se vierte (con el poso de la memoria, y su bagaje vital y cultural) sobre la realidad que la circunda. Es una mirada que cuestiona, que se detiene morosamente sobre la naturaleza, sobre el mundo, tratando quizá de hallarle sentido ${ }^{2}$. "Aunque soy muy activa y dinámica, busco esa mirada lenta sobre las cosas que te dé la sensación de vivir tú el tiempo en lugar de que el tiempo te viva a ti" —afirmaba Julia Otxoa en una entrevista (Moyano) en 2008, a raíz de la publicación de su poemario La lentitud de la luz-. "Hay una urgente necesidad de la lentitud de la mirada sobre el mundo", reafirmaba en otra entrevista de 2014 (Enamorado, 2014: 35). La mirada se descubre perpleja ante la injusticia, la violencia, la mentira, la insolidaridad, la pobreza. Ante esa perplejidad la aproximación realista se vuelve insuficiente, y lo insólito surgirá como una vía posible para dar cuenta del horror ${ }^{3}$.

Por otro lado, la memoria de la que se nutre esa mirada es individual, pero también familiar y colectiva. Julia Otxoa no ha dejado de contar (Benegas y Munárriz, 1997; Moyano, 2008; Enamorado, 2014) cómo se le transmitió desde la infancia la memoria de la brutalidad de los hechos que acabaron con el asesinato durante la Guerra Civil de su abuelo y de sus tíos. Siempre ha añadido, sin embargo, que "[mi familia] jamás me alentó en el rencor o el odio" (Benegas y Munárriz, 1997: 172), lo que le ha permitido tener un posicionamiento analítico y reflexivo ante la violencia en todas sus formas.

Buena parte de la obra de Julia Otxoa es percibida por el lector como un espacio para la reflexión ante la barbarie, pero también para restituir la memoria mientras no llega la completa restitución oficial. Desde distintos enfoques, distintos momentos en el tiempo,

\footnotetext{
2 "El siglo a mi alrededor es incomprensible" leemos en su poema "Oración para Frank Kafka", recogido en Al calor de un lápiz (2000).

${ }^{3}$ Por lo general, los estudios críticos existentes sobre la obra de Julia Otxoa se han centrado precisamente en la temática y las categorías estéticas que pueden aplicarse a su obra, si bien han esquivado los procedimientos concretos de que se sirve la autora. Los más solventes en el ámbito de la minificción son los de Pérez Bustamante (2009), Encinar (2012), Carrillo Martín (2012) y Andres-Suárez (2018).
} 
y distintas modalidades artísticas, Julia Otxoa convierte su escritura y su obra gráfica en un extendido homenaje a sus familiares, y a los miles de asesinados durante la Guerra Civil, que no tienen voz. Su compromiso de relatar el horror quedó expresado de forma trágica en el poema 59 de Jardín de arena (2014):

Sé que debo hacerlo

miles de esqueletos claman insepultos tras la ventana,

no pertenecen al registro oficial de víctimas,

tan solo son pobres huesos del bando perdedor

apenas nada para los cómplices del olvido (Otxoa, 2014: 62).

Apoyada en la autorreferencialidad, también la poesía visual y la narrativa breve se suman a este poema escrito in memoriam de su abuelo Balbino. "Penal de Burgos invierno 1938" (en recuerdo de su tío Clemente, muerto de frío) u "Homenaje a mi abuelo BalbinoFosas españolas 1936-2019” son solo dos muestras de las tantísimas que nos ofrecen sus montajes fotográficos de poesía visual. El homenaje continúa en sus volúmenes de narrativa breve, que incluyen de forma continua la contribución de la autora a la recuperación de la memoria histórica: "La mosquita cadáver", de Un extraño envío (2006), "La confesión", de Escena de familia con fantasma (2013), o "El escalador" de Confesiones de una mosca (2018).

Resulta obvio que la escritora no concibe una estética al margen de la ética, y tampoco una literatura distanciada de su tiempo ${ }^{4}$, ya que entiende la obra del artista como testigo de la Historia. Su escritura es una voz que - mediante la actualización, la revisión, la recuperación - desea contribuir a la victoria sobre el olvido. Desde su concepción de las artes, su escritura y su obra gráfica se explican como un acto de responsabilidad: "Pienso que los escritores y los artistas deben estar cosidos a su tiempo y ante la barbarie y el dolor del otro no podemos mirar hacia otro lado ${ }^{5}$. Es que es tan obvio que no lo tengo que pensar" (Moyano, 2008).

En su minificción han incidido con fuerza las vicisitudes históricas que han determinado su contexto vital. Nacida en San Sebastián en 1953 dos problemáticas centrales (dos materializaciones distintas de una misma violencia) han marcado su vida y su producción literaria y artística: la Guerra Civil y ETA. Su compromiso con el tiempo que le ha tocado vivir (también con el de su más inmediata contemporaneidad) es uno de los aspectos que perfila la singularidad de la minificción de Julia Otxoa a la que ya hemos aludido. Tal vez solo el escritor Juan Pedro Aparicio, también cultivador del género del microrrelato, se sitúa en la misma órbita al utilizar como materia prima de algunos de sus cuánticos la revisión histórica de la Guerra Civil y la dictadura franquista ${ }^{6}$, y al presentarla desde los ángulos de lo insólito.

\footnotetext{
4 "No concibo la estética si no es como proceso ético al mismo tiempo" (Otxoa en Rosal, 2006: 216); "Reflejar mi tiempo es mi objetivo" (Otxoa en Sala, 2002).

5 "No va con mi modo de entender la escritura mirar para otro lado cuando lo terrible a menudo sucede a nuestro lado" (Otxoa en Enamorado, 2014: 32).

${ }^{6}$ La mitad del diablo (2006) y El juego del diábolo (2008).
} 


\section{LA DISTORSIÓN Y EL EQUILIBRIO ENTRE EL DISTANCIAMIENTO Y LA IDENTIFICACIÓN}

Como hemos advertido, ni la mirada sobre este pasado, ni sobre el presente más cercano (con las terribles consecuencias de las crisis económicas, la manipulación y corrupción de los políticos, la injusticia social, o el abandono de los ciudadanos por parte de las instituciones) suele desembocar en la obra de Julia Otxoa en una fabulación realista. Parecería que la representación mimética de la realidad no es suficiente para alterar las conciencias. Hemos llegado a normalizar lo real, y tan habituados estamos a presenciar la injusticia, que apenas podemos ya verla. Quizá por ello la escritora amplifica esa realidad, la altera, la hiperboliza en ocasiones, para que se nos presente en toda su dimensión. $\mathrm{Y}$ al acceder a esa nueva realidad "imaginada" y distorsionada por Julia Otxoa, el lector la reconoce por fin en la suya propia y es capaz de tomar conciencia e interrogarse sobre ella.

La distorsión de la realidad llega a través del absurdo, "un absurdo visto desde la fecunda herencia de la mirada kafkiana" — como señala atinadamente José María Merino en su prólogo a Un extraño envío (2006: 8) ${ }^{7}$-, o del extrañamiento, atributos consustanciales a la realidad, según la percepción de lo real considerada por Julia Otxoa:

Yo diría que a menudo la realidad se presenta ante nosotros con caracteres marcadamente absurdos. Es decir, el absurdo, como la alegría, el dolor, la crueldad, la belleza, etc., forma parte de la realidad. Aunque, a veces, como ocurre en nuestros días, la pérdida del bienestar social, la injusticia, la desesperanza de una sociedad que ha visto mermados seriamente sus derechos esenciales: trabajo, casa, educación, sanidad, etc., marcan un tono, un contexto, en el que el absurdo de la situación en general pesa más que otros factores (Enamorado, 2014: 32).

Las conexiones con el esperpento de Valle-Inclán, con el expresionismo, o con lo grotesco son evidentes. Como Valle, Julia Otxoa parece defender que solo con una estética deformada o deformadora puede representarse una realidad ya deformada ${ }^{8}$. Pero, además, esta mirada distorsionadora está al servicio del compromiso de la autora, ya que lo esperpéntico, lo grotesco, lo absurdo, lo hiperbólico impiden la identificación, pero al mismo tiempo — por medio de un efecto de distanciamiento que guarda paralelismos con la propuesta de Brecht - predispone a que su lector abra los ojos y se cuestione de forma crítica la realidad.

\footnotetext{
7 También Luis Mateo Díez se fijaba en esta ascendencia en "Fabulaciones actuales", su texto preliminar a Confesiones de una mosca: "Los relatos de Julia Otxoa, en los que puede adivinarse un rasgo kafkiano, una herencia esperpéntica y, algo más allá, en su fértil imaginación, destellos surrealistas y un humor satírico que hasta puede llevarnos a la literatura del absurdo, como en el variado tamiz de algunas tradiciones narrativas entrecruzadas y que derivan en la escritura de la autora con renovada modernidad" (Otxoa, 2018: 8).

8 "El sentido trágico de la vida española sólo puede darse con una estética sistemáticamente deformada", sentencia Max Estrella en la famosa Escena XII de Luces de Bohemia.
} 
El distanciamiento no puede ser, sin embargo, tan absoluto que impida el reconocimiento. Si la escritora desea que el lector adopte una misma postura crítica ante una realidad deshumanizada compartida, debe dejar algunos amarres que permitan la conexión entre la realidad intratextual y la extratextual. Este difícil equilibrio que consigue la autora entre el distanciamiento y la identificación de una realidad histórica referencial es uno de sus rasgos más distintivos, y una de las razones por la que la mayor parte de su narrativa breve se sitúa fuera de las fronteras de lo fantástico. Ciertamente, para que el efecto fantástico tenga lugar, es decir, para que aflore en el lector la inquietud, el miedo, o el desasosiego "ante la incapacidad de concebir la coexistencia de lo posible y lo imposible" (Roas, 2011: 31), el lector debe identificar, en primer lugar, el espacio intratextual con su realidad extratextual. El hecho de que la realidad intratextual en la obra de Julia Otxoa se presente con frecuencia desde la extrañeza y la distorsión promueve que las conexiones con la cotidianeidad extratextual (aun relevantes para las intenciones de la autora) se reduzcan al mínimo necesario.

La indispensable cercanía se limita a la identificación por parte del lector de unas mismas problemáticas a las que la literatura de Julia Otxoa nos enfrenta. El distanciamiento, sin embargo, llega con la convergencia de varios procedimientos empleados, empezando por la mirada distorsionadora a la que nos venimos refiriendo.

El escritor José María Merino aludía indirectamente a una de estas estrategias de distanciamiento cuando en su prólogo a Un extraño envío reparaba en que la toponimia y la geografía elegidas por Julia Otxoa para contextualizar sus relatos "aunque tenga nombre, y con ello una supuesta certeza de crónica, siempre deja asomar la sugestión de lo imaginario" (Otxoa, 2006: 7). Siguiendo la estela de Merino, Ángeles Encinar ahondaba con posterioridad en este mismo aspecto idiosincrásico del volumen de relatos de 2006, y subrayaba que los espacios narrativos en los que se desarrollaban sus historias no eran fácilmente reconocibles para un lector español. Con mucha sagacidad, justificaba Encinar esta tónica presente en Un extraño envío - extrapolable, de hecho, a toda la narrativa breve de Julia Otxoa-, por la voluntad expresa de descontextualizar nuestra realidad geográfica inmediata, que, sin embargo, no impide reconocer "la referencialidad anecdótica a la realidad social y política de nuestra historia actual" (Encinar, 2012: 138).

La casi total desconexión con nuestras coordenadas geográficas más cercanas, que desemboca en lugares que son al mismo tiempo no lugares, se une a la ausencia de concreción temporal, como un nuevo procedimiento que contribuye al alejamiento. Las referencias temporales son de carácter vago, y se circunscriben por lo general a la mera localización de la historia en el pasado, el presente o el futuro, siendo estas instancias intercambiables. Aunque la indeterminación o disolución de coordenadas espaciotemporales viene en cierto modo impuesta por la brevedad y la condensación propias del microrrelato, su elección contribuye al mismo tiempo a transmitir la impresión de validez universal de lo relatado y lo sugerido, esencial en una literatura nacida del compromiso de la autora con su tiempo, pero sabedora de que la Historia tiende a la repetición. 
Julia Otxoa experimenta de forma recurrente con la disolución de espacios reales, que se dilatan, pierden sus contornos, o se destruyen. En todos los casos, el espacio se torna amenazante para aquel que lo habita. Esta ruptura de las leyes de la perspectiva, y de la proporción evoca los decorados expresionistas, con las distorsiones y deformaciones propias de una estética que pierde el interés en la realidad objetiva, pero también enlaza directamente con el género fantástico ${ }^{9}$.

Entre las variantes ensayadas nos topamos con aquellos espacios absorbentes que van engullendo los huecos habitables, arrinconando progresivamente a sus habitantes. Los ecos de "Casa tomada" de Cortázar son evidentes en el relato "Un extraño envío" (Un extraño envío, 2006) donde se produce la misma acción de repliegue en la protagonista. Lo insostenible de su situación ante la invasión del espacio que está experimentando lo expone ella misma en la sexta carta que remite a su marido:

Mi situación es cada vez más desesperada, mi espacio vital se ha reducido considerablemente, no ya solo debido a las pilas de libros y diccionarios desparramados por el suelo, sobre las mesas, sobre las sillas, sino también al hecho de que nuestra pequeña sala de estar se ha convertido en el único lugar donde me siento segura (Otxoa, 2006: 67).

La atmósfera inquietante se intensifica cuando descubrimos que las cartas de la protagonista han dejado de ser contestadas.

Otras veces la angustia y el desasosiego llega con espacios que se expanden y dilatan, a veces invadidos por toda suerte de peligros. En el relato "Teléfono" (Un extraño envío, 2006) el protagonista narra en primera persona (tan propicia para lo fantástico), en medio de la desesperación, las razones de no atender al teléfono. Las dimensiones de la casa, y los peligros a los que debe enfrentarse al atravesar el largo corredor - que roza lo sobrenatural, con la presencia, por ejemplo, de "esos extraños perros, siempre nerviosos, excitados, con esa especie de niebla de otro mundo en la mirada" (Otxoa, 2006: 49)— le impiden descolgar a tiempo. La sensación de invasión y de cercana expulsión en un ambiente de creciente pesadilla también llega para el protagonista de este relato: "Todo el corredor es entonces un eco multiplicado de sombras frías envolviéndome cual tela de araña, para que no llegue, para que nunca llegue" (Otxoa, 2006: 49).

En Confesiones de una mosca (2018) se acentúa la experimentación con la disolución espacial desde la vertiente fantástica. "Limpieza de oficinas" nos ofrece la dilatación progresiva del espacio abierto, en concreto del trayecto que debe realizar la protagonista desde su casa y su trabajo como limpiadora en unos grandes almacenes. La normalidad con que se presenta la realidad (que conecta así con la cotidianidad extratextual del lector) le impide acertar a comprender racionalmente la irrupción de lo imposible. La cada vez mayor distancia entre los dos puntos va complicando gradualmente el acontecimiento

\footnotetext{
${ }^{9}$ Recordemos que los relatos de Julia Otxoa mantienen un mínimo de referencialidad que permite al lector reconocer los perfiles de la realidad intratextual, y asumirla como propia. Estas anclas echadas en lo real posibilitan aún la emersión, en algunos relatos, del efecto fantástico y con él la inquietud del lector.
} 
fantástico, que finaliza con la imposibilidad no solo de llegar a su destino, sino de regresar a su origen, lo que ha dejado a la protagonista "en medio de ningún lugar", "como un espantapájaros" (Otxoa, 2018: 32).

Las consecuencias del cambio sobrenatural de las coordenadas espaciales se plantean, asimismo, desde una nueva perspectiva en el microrrelato "Extravío", donde toda una ciudad pierde sus referentes sumiéndose en la desorientación y el caos, con el que deciden convivir tras una consulta en referéndum. No obstante, la atmósfera de miedo y pesadilla se manifiesta aún en un grado mayor en la distorsión espacio-temporal que origina el microrrelato "Viaje" (Otxoa, 2018: 95), también perteneciente al volumen Confesiones de una mosca. La escritora disemina a lo largo del texto varios indicios que guían al lector hacia el terror de imaginarse en el interior del autobús que recorre circularmente una planicie desértica ("Diríase que alguien ha dibujado caprichosamente una negra culebra de asfalto en medio de la nada"). Y, si bien el viaje en autobús, circular e infinito, tiene algunas paradas, los lugares a los que el viajero creía dirigirse no existen. El que decide bajar, "queda allí parado junto a su maleta, azotado por el viento como un espantapájaros en el paisaje vacío", imbuido por la misma desorientación que la mujer de "Limpieza de oficinas". Algunos vuelven a subir, y su estado al regresar no es menos sobrecogedor: "desorientados y cubiertos de polvo como extraños espectros" acaban conformándose con ver repetidamente a través de las sucias ventanillas el mismo paisaje distópico.

Junto a los procedimientos referidos (efecto distorsionador, disolución de la trama, uso de nombres propios y toponímicos que evocan otras nacionalidades y geografías, y la disolución de coordenadas espacio-temporales) no podemos olvidarnos, asimismo, del humor, cuya importancia en la obra narrativa de Julia Otxoa ya ha sido ampliamente referida por la crítica ${ }^{10}$. El humor no solo favorece la elección de una mirada esperpéntica y absurda sobre la realidad, sino que acentúa el distanciamiento y conduce a la transformación, ya que es - como asegura la escritora - "el gran cuestionador de las verdades inmutables, del pensamiento único, tan peligroso para la libertad" (Enamorado, 2014: 34).

\section{DISTOPÍAS MÍNIMAS}

Las estéticas deformadoras que originan microrrelatos como los mencionados "Viaje", "Limpieza de oficinas" o "Teléfono" son las más habituales de entre todas las modalidades de las que se sirve Julia Otxoa para presentar el mundo ficcional de su narrativa breve.

La mirada que derrama la escritora sobre la realidad entorno se traslada al universo textual después de pasar por el filtro de lo fantástico ("Viaje"), lo maravilloso ("Hombre y niño"), lo simbólico-alegórico (“Un pequeño banquete”), lo surrealista ("Los escombros del día"), lo mitológico ("Mujeres imantadas"), lo absurdo ("El notario de los nuevos

${ }^{10}$ Merino (2006), Pérez Bustamante (2009), Encinar (2012, 2013), Andres-Suárez (2018). 
tiempos"), lo esperpéntico o grotesco ("Cena de Navidad"), lo proyectivo (“Cajeros automáticos"), y en mucha menor medida, también lo realista ("Ortopedia") ${ }^{11}$.

No obstante, ninguna de estas modulaciones colindantes suele hallarse de manera pura y aislada en un solo microrrelato, sino que participan en diversas combinaciones en las que están presentes en mayor o menor grado. Si bien la crítica que se ha aproximado a la narrativa de Julia Otxoa ha coincidido, por lo general, en apuntar la estética esperpéntica, kafkiana, surrealista o absurda (y la confluencia de todas ellas) como característica determinante de su producción, no se halla ninguna referencia explícita a la fértil experimentación por parte de la autora con el género de la ficción proyectiva, cuya presencia se enfatiza, sin embargo, en su último volumen de microficción. En el breve espacio del relato breve o del microrrelato, Julia Otxoa recurre con asiduidad a la construcción de un mundo posible que parte de la proyección del mundo que la rodea. Dada la visión descorazonadora que prodiga la autora hacia el ser humano y la sociedad contemporánea, la vertiente de esas ficciones no puede ser otra que distópica.

En los volúmenes publicados con anterioridad a Confesiones de una mosca ya había adelantado Julia Otxoa su querencia por la ciencia ficción (a veces en las fronteras de lo fantástico). Y ya entonces exploraba la autora las posibilidades del género para proyectar una sociedad deshumanizada que funcionara como reflejo deformado de la nuestra. En "Las desventuras de Frankenstein", incluido en el volumen Escena de familia con fantasma (2013), un viaje en el tiempo permitía a la criatura de Mary Shelley trasladarse al siglo XXI, donde horrorizado conocía a los nuevos monstruos del futuro (nuestro presente) ${ }^{12}$. Esa otra monstruosidad, que le produce lágrimas amargas, le llevarán a regresar al pasado y pedirle a su creadora que desista de imaginarlo:

Pero ahora todo había cambiado; el mundo vivía atemorizado por los banqueros sin corazón succionando bolsillos. Con los grandes magnates que compraban países y los tiraban luego a la basura cuando se cansaban de jugar. Con los gobernantes locos que se divertían provocando guerras, construyendo su poder sobre montañas de muertos. Sí, el siglo XXI se había convertido en una auténtica película de terror (Otxoa, 2013: 58).

En el mismo volumen de 2013 se incluía, asimismo, el microrrelato "Centenario del Matadero Municipal”, donde se aludía de forma transversal a una posible realidad distópica, en la que los recortes en educación llegados con la crisis habían acabado con el cierre casi total de las universidades en todo el estado. Sin embargo, es en Confesiones de una mosca donde se evidencia de forma más palmaria el cultivo de esta ramificación de lo insólito, con la escritura de verdaderas distopías en miniatura. Los microrrelatos distópicos de Julia Otxoa surgen de su interés no solo por el pasado, sino también por el

\footnotetext{
11 Todos los títulos que se aducen como ejemplificaciones de las distintas variantes pertenecen al volumen de Confesiones de una mosca (2018).

${ }^{12}$ En sentido estricto, este microrrelato se situaría fuera de los límites de la distopía, ya que el futuro al que ha viajado Frankenstein lo es solo para él. La realidad que horroriza a Frankenstein mimetiza la nuestra; puede producirnos el mismo espanto que a Frankenstein, pero es nuestro presente más tangible y no un futuro distópico.
} 
futuro en el que puede desembocar tanto ese pasado como el presente, y enlaza de forma directa con el espíritu comprometido y crítico que vertebra sus textos. Estas minificciones constituyen una clara muestra del procedimiento que comentábamos más arriba, según el cual Julia Otxoa se distancia de una contextualización concreta al tiempo que señala directamente a la misma. Así, la representación distópica (aun hiperbólica y grotesca) es planteada como posibilidad (mundo posible) y, por tanto, puede ser entendida como advertencia al ser humano contemporáneo.

"Confesiones de una mosca", microrrelato del volumen homónimo, elige como realidad distópica el aniquilamiento de todos los habitantes de una ciudad, después de intentar que contestaran - sin éxito, y a pesar de las amenazas - a las preguntas del “interrogador". El relato de las consecuencias de tal destrucción será conducido a través del humor, que predispone al cuestionamiento. Las moscas llegaron atraídas por los innumerables cadáveres apilados en todas las ciudades en que se repitieron los sucesos, y el problema de sanidad pública en que esto derivó promovió la celebración de congresos internacionales, y con ellos, la llegada del turismo. La recuperación económica que trajo consigo no consiguió, sin embargo, frenar la extinción de la ciudad. La representación distópica se nos muestra distanciada a causa de la mirada claramente grotesca (surgida de la unión del terror y el humor; de lo monstruoso y lo paródico) con que es creada. Pero a pesar del proceso de amplificación esperpéntica que lleva a cabo la autora, resuenan los ecos de la Guerra Civil y la represión franquista, sin que necesariamente tenga que ser su referente. En estos ecos, en esta base real identificable, reside la proximidad entre realidad intratextual y extratextual, puesto que Julia Otxoa cuenta con que el lector implícito al que va dirigido el relato pueda reconocer las conexiones; hubo un tiempo en que los sucesos narrados no fueron tan distópicos en España. Siguen sin serlo en otras latitudes.

En Confesiones de una mosca, Julia Otxoa dedica la mayor parte de las distopías mínimas que contiene el volumen a las crisis económicas y a todos los horrores que desencadenan. Los microrrelatos "Oficina de empleo", "El jueves, milagro", "Cajeros automáticos", "Decorados", "Una nueva era" son percibidos como integrantes de una misma serie, en la que cada una de las configuraciones de un mundo posible distópico que se lleva a cabo actualiza una problemática distinta acaecida con la crisis económica. Pese a que las distopías - como es habitual en la narrativa breve de Julia Otxoa - no están contextualizadas ni espacial ni temporalmente, el lector no puede evitar conectar la realidad proyectada por la autora con la crisis financiera de 2007-2008, y la gran recesión que trajo consigo ${ }^{13}$. Los microrrelatos mencionados - algunos de los cuales fueron redactados en torno a 2013, ya en imprenta Escena de familia con fantasma - trasladan al lector a la explosión de las hipotecas de alto riesgo, a la crisis alimentaria global, al crecimiento del desempleo, o a las desigualdades de clase; todo ello ligado a la crisis económica de 2008.

\footnotetext{
${ }^{13}$ El hecho de que el lector actual pudiera contemplar, además, la crisis económica del 2020 como posible referente a las ficciones proyectivas que imagina Julia Otxoa apoya el carácter universal y circular de las distintas problemáticas abordadas, facilitado por la función de descontextualización.
} 
En "Oficina de empleo", una escena reconocible por el lector como "familiar", y "habitual" en la sociedad contemporánea, como es la solicitud de trabajo en la Oficina de empleo, es ahora grotesca. El número de parados ha crecido tanto que la solicitud debe ir acompañada del ofrecimiento a cambio de algún órgano o miembro del solicitante, con el fin de que aquella se tome siquiera en consideración. A través de la aplicación de una estética esperpéntica, deformadora, se subraya la crítica a la desprotección de las instituciones, y a la falta de humanidad de unos burócratas que son incapaces de ver a sus semejantes (en una especie de justicia poética, el propio sistema acabará atacando a sus funcionarios).

El absurdo es la estética dominante en la construcción del microrrelato "El jueves, milagro", donde la crisis económica, que ha dejado "una imparable cifra de más de cinco millones de parados" (no pasa por alto la correspondencia con las cifras de 2013 en España), vuelve a proporcionarnos una nueva realidad distópica. El director del Banco Nacional se ofrece "en solidaridad con los más necesitados" (Otxoa, 2018: 17) a poner un huevo de oro cada primer jueves de mes. Los nefastos resultados de la puesta, muy lejos de lo prometido, y los discursos del primer ministro, pidiendo paciencia y prometiendo mejores resultados del Banco central, revelan la desconfianza en la actuación de los bancos (que nunca obrarán el milagro de amparar a los más desfavorecidos) y en el manejo de la economía por parte de los gobiernos.

"Cajeros automáticos" (Otxoa, 2018: 48) presenta una nueva cara de esta crisis. En este caso, las consecuencias de la falta de liquidez bancaria (de nuevo resuenan los ecos de las primeras consecuencias de la crisis de 2008) han llevado al primer ministro a tomar la medida de sustituir el dinero que sale de los cajeros por puños de hierro que golpean a los usuarios, y más adelante, cuando "las cosas han mejorado un poco", por alimentos racionados ("a veces un huevo, otras un pimiento, incluso un conejo").

El microrrelato "Decorados" convierte en una terrible epidemia los suicidios por impago, que el lector conecta de forma inmediata con una de las consecuencias más funestas de nuestra crisis financiera. Los suicidios que se sucedían imparables entre 2012 y 2013 debieron de servir, sin duda, de trágica inspiración a la autora para redactar este microrrelato, que se publicó por primera vez - antes de integrarse en Confesiones de una mosca - el 17 de marzo de 2013, en el Blog "La nave de los locos", de Fernando Valls. La aproximación distópica por la que opta la autora, con la multiplicación de cadáveres con cada amanecer, el aspecto lunar de la ciudad, y la colocación —por orden gubernamental - de maniquíes en terrazas y teatros para lograr "cierto aire de normalidad" (Otxoa, 2018: 65) subraya de manera más evidente la deshumanización de la sociedad contemporánea.

Son muchísimos más los escenarios distópicos que nos ofrece Confesiones de una mosca donde la ficción proyectiva revela su función de denuncia. La injusticia social asoma, por ejemplo, en "Anochecer en la ciudad", a través de una sociedad en que los dueños de los comercios, acabada la jornada laboral, lanzan a sus empleados bajo las persianas y los decapitan con un violento cierre. La inmigración se aborda en "Cita en la 
embajada", al presentar un mundo en el que el embajador, gobernante dictatorial, bajo cuya apariencia se presume un autómata, ha decidido "colocar leones en la frontera como medida disuasoria ante las masivas oleadas de inmigrantes" (Otxoa, 2018: 52).

Es evidente que la aproximación esperpéntica que tienen como común denominador todas estas representaciones distópicas, donde lo cómico (un "humor oscuro, en ocasiones macabro e incluso sangriento" ${ }^{14}$ ) se mezcla con el horror (lo terrible, lo inquietante, lo infame) da como resultado auténticas tragedias grotescas. En efecto, buena parte de la narrativa breve de Julia Otxoa $-\mathrm{y}$ las distopías mínimas constituyen una buena muestra - responde a la finalidad que se persigue con el uso de la categoría estética de lo grotesco, tal y como la sintetiza de manera oportuna David Roas:

Se trata, en definitiva, de deformar los límites de lo real, de llevarlos hasta la caricatura, [...] para provocar la risa del lector, al mismo tiempo que lo impresiona negativamente mediante el carácter monstruoso, macabro, siniestro o simplemente repugnante de los seres y situaciones representados, siempre - a mi entender - con el objetivo esencial de revelar el absurdo y el sinsentido del mundo y el yo (Roas, 2011: 73).

A pesar del efecto distanciador de la hipérbole y la distorsión (dos propiedades inherentes a lo grotesco), así como del humor trágico, Julia Otxoa sabe combinar inteligentemente los dos componentes que convergen en lo grotesco. El esperpento hace asomar la risa, pero esta se contiene ante lo trágico de la representación. Pese a no existir una equivalencia completa entre realidad intratextual y extratextual, aún podemos percibir las sujeciones a nuestro contexto conocido, y comprender esa certeza es lo que detiene la carcajada.

\section{EL LECTOR CÓMPLICE}

Una literatura como la de Julia Otxoa, desarrollada en buena parte - como hemos tenido ocasión de comprobar - en torno al compromiso ético y la denuncia, a través de las distintas modalidades de lo insólito, tiene presente más que ninguna otra la voz del interlocutor. Ya se sirva de la palabra para su poesía o minificción, ya de la imagen para su obra gráfica, o incluso de la confluencia de ambas para su poesía visual, Julia Otxoa establece el inicio de una comunicación, que parte de la voluntad de interpelar al lector o espectador. La escritura de Julia Otxoa materializa aquella afirmación con la que Carmen Martín Gaite se refería a su propia búsqueda del interlocutor, cuando recuperando las palabras unamunianas, exponía: "No sé hablar si no veo unos ojos que me miran y no siento detrás de ellos un espíritu que me atiende” (Martín Gaite, 1983: 115).

El espíritu que atiende la voz narrativa de Julia Otxoa no puede quedarse dentro de los límites del texto. Cuando la autora se propone a través de su obra recuperar la memoria de los olvidados en fosas comunes y cunetas (“El escalador”), o cuando representa

\footnotetext{
${ }^{14}$ Así definía José María Merino el humor que percibía en los relatos de la autora compilados en Un extraño envio, que el escritor prologa en 2006 (Merino, 2006: 10).
} 
brutales estampas de una realidad distópica en la que ha desembocado la crisis económica (“Oficina de empleo", "Decorados") confía en que el pensamiento subyacente traspase los límites del texto.

La postura ética que Julia Otxoa se reclama a sí misma, como artista de su tiempo, cuando afirma que no se puede mirar para otro lado cuando a nuestro lado hay tanto horror, es trasladada al lector. No desde la exhortación, ni desde el discurso político (muchos de sus microrrelatos apuntan a lo dañino de los discursos que son puro lenguaje, pura retórica), tampoco a través de un mensaje explícito, sino provocando en él los mismos o nuevos interrogantes, la toma de conciencia, la continuación de las reflexiones que motivaron sus historias, las cuales pueden concluir dejando al lector suspendido de un sinfín de interpretaciones. En consecuencia, para continuar la comunicación que le brindan los textos de Julia Otxoa el interlocutor al que van dirigidos se verá obligado a reconectar activamente parte de las significaciones presentes y ausentes en el texto, cooperando en la generación del sentido.

Domingo Ródenas, en el estimulante artículo "Contar callando y otras leyes del microrrelato" (2008), sintetizó con rigor y acierto esta necesaria cooperación del lector para rellenar los vacíos que el cultivador o cultivadora de las formas breves e hiperbreves coloca en el texto:

el lector, siguiendo un principio tácito de cooperación comunicativa, tiende a reducir el grado de indeterminación del texto, efectuando suposiciones, inferencias, tendiendo puentes causales o consecutivos; de este modo, cuanto menos sea la irresolución, menor será también el esfuerzo participativo del lector. Y, tratándose de una relación de proporcionalidad directa, cuanto más incompleto sea el mundo ficcional, mayor implicación será precisa por parte del lector, aun cuando este siempre pueda limitarse a una lectura somera o literal —empobrecida, por tanto—- del texto (Ródenas 2008: 7).

Si la concisión, la elipsis, y la irresolución propias de la forma del microrrelato exigen un lector atento y colaborativo que complete los huecos, esta exigencia se acentúa para la minificción de Julia Otxoa, debido a la construcción en suspensión, ya comentada, por la que se decanta la autora, que implica una mayor indeterminación, y por tanto, una mayor complejidad exegética.

A esta participación activa que se demanda del lector aludía uno de los personajes que cruzan el universo creado en Un extraño envio (Relatos breves), mención que puede ser entendida como una insinuación de carácter metaliterario de la propia autora. La hallamos en boca de Jules Feltrinelli, entrevistado tras haber conocido a su doble, y haber muerto este en extrañas circunstancias. En la "Entrevista a Jules Feltrinelli" (Un extraño envío, 2006), construida desde la vertiente lúdica y cómica que despliega parte de la producción de Otxoa, y con la revisita a uno de los motivos fantásticos por antonomasia, la autora va diseminando toda una serie de imprecisiones y vaguedades sobre el suceso que ha motivado el diálogo. Estas elipsis a través del uso de pronombres indefinidos ("alguien tan peligroso", "un doble de aquellas características”, “¿cómo pudo ocurrir aquello?”) llegan al punto climático cuando el entrevistador pide más detalles del encuentro ("JOHN 
MILTON.- ¿No va a contar nada de cómo ocurrieron las cosas para llegar a un final tan increíble?") y el entrevistado responde, en lo que supone un control sobre su historia, pero también sobre el texto: "JULES FELTRINELLI.- No, no voy a hacerlo, prefiero que sea el lector quien interprete, dejar todas las posibilidades abiertas" (Otxoa, 2006: 127).

La concepción del lector como activo cooperante del proceso de escritura y la interpretación de sus claves vuelve a aflorar en el volumen Escena de familia con fantasma a través del microrrelato "No hay tiempo para escribir una carta". La meditación acerca de la dificultad de entregarse con calma a la correspondencia debido a la vida de prisa que nos oprime se ejemplifica con tres breves cartas que redactó un emisor abrumado por el tiempo. A partir de estas tres posibilidades en las que el lenguaje adelgaza y reduce cada vez más unas ideas en torno al nacionalismo, el narrador propone con el final del texto un juego al lector, que deja patente la postura crítica y activa que se espera de él: "El estresado escribiente escogió una de ellas; en la voluntad del lector está acertar cuál de las tres fue la de su elección" (Otxoa, 2013: 125)

La ficcionalización de la reflexión metaliteraria (presente en mayor o menor grado en todos sus volúmenes de narrativa breve) desemboca en otras ocasiones en la visión paródica de un lector (que ya nos salió al paso al mencionar el microrrelato "Corrientes literarias", de Confesiones de una mosca) demasiado preocupado por atrapar toda referencia no suficientemente explicitada, completar cualquier vacío de información, o desentrañar todos los sentidos del texto. En "El lector", microrrelato perteneciente al volumen Un extraño envío, Julia Otxoa dibuja la actitud extrema del lector que no puede lidiar con la indeterminación textual y lleva hasta los límites su papel cooperador. Descifrar el significado, el alcance, las razones de la elección de un sustantivo u otro en tan solo una única frase puede llevar al meticuloso lector a años de investigación. Sin embargo, será en vano; "el fin de sus días le sorprenderá sin haber pasado de esa primera frase, porque irremediablemente la búsqueda de conocimiento le lleva de unas palabras a otras y estas a otras más lejanas, como si cada definición encerrara a su vez una cadena interminable de significados diferentes, un infinito paisaje de huellas cruzadas" (Otxoa, 2006: 119). A pesar de la pequeña dosis de comicidad que contiene el relato, sigue siendo válida la meditación metaliteraria a partir de la que se origina, y también en la que afluye. Por un lado, la escritura (con la formulación elegida, los vocablos seleccionados, las imágenes elaboradas) no puede darse al margen de la lectura posterior y las posibilidades $\mathrm{u}$ opciones interpretativas. En otras palabras, no se puede hablar/escribir sin tener presentes unos ojos que mirarán y atenderán el texto. Por otro lado, la ineficacia o fracaso de la búsqueda concreta del lector presentado por el narrador aludiría a la imposibilidad de lograr una interpretación única y verdadera, extrapolable a la narrativa de Otxoa.

Un nuevo lector ávido de verdades y exactitudes interpretativas vuelve a asomar en "La mujer con botas", incluido en Escena de familia con fantasma. La reflexión metaficcional irrumpe bruscamente en el relato cuando la narración en primera persona con la que se inicia el texto acerca de una extraña mujer a punto de defender su tesis queda interrumpida bruscamente. En el momento en que se iba a desvelar el título de la tesis, un 
nuevo narrador en tercera persona toma control sobre el texto, informando de la elipsis que no ha sido completada, y que deja al lector perplejo. El narrador se entrega a la formulación de algunas hipótesis acerca del modo como afrontarán los lectores, según su tipología, este vacío de sentido. La atención la ocupa el lector que no se conforma con la existencia de esos vacíos, y que pondrá en marcha todas las estrategias que estén en su mano para completarlos. En su empeño y afán por el desciframiento, este lector puede convertirse "en un verdadero especialista en textos crípticos, inacabados, de tal modo que, habituado a este tipo de literatura, no encuentre placer alguno en los libros cuyos relatos se muestran totalmente claros, perfectamente terminados" (Otxoa, 2013: 124).

La insistencia, por parte de la escritora, en ficcionalizar desde la hipérbole paródica - y en distintos momentos de su trayectoria narrativa - al lector demasiado preocupado por desvelar todas las claves del texto parece conectar con las aspiraciones contrarias de su propia minificción. Su lector cómplice, su interlocutor, no es aquel que busca obsesiva y desesperadamente una interpretación satisfactoria y concluyente, sino el que participa de lo sugerido, lo suspendido, y sobre todo de la meditación que, sobre la condición humana o la realidad histórica, se abre camino en cada texto.

\section{CIERRE}

El análisis de la minificción de Julia Otxoa revela de forma ostensible la voluntad de la autora de "transitar por carreteras no señalizadas" (2017) ${ }^{15}$. La mayor parte de sus piezas narrativas se sitúa en las zonas umbrales, fronterizas, híbridas, ya sea entre géneros, ya sea entre las modalidades de lo insólito; lejos por tanto de las limitadoras categorías puras.

La forma, el lenguaje, y el continente o soporte que acoge sus distorsiones mínimas se ponen al servicio de trasladar al lector (su interlocutor) el mundo compartido que se presenta ante sus ojos, brutal y deshumanizado. La literatura de Julia Otxoa es una literatura fruto de no apartar la mirada, y el modo de representación elegido para vehicular esa mirada y canalizar el horror, sirviéndose de lo grotesco y lo deformado, es la vía más competente para despertar al lector de su adormecimiento conformista, causado, entre otras razones, por la "solemnidad asnal" de los discursos.

Por ello, siempre huyendo de toda retórica, y muy lejos de la equidistancia del protagonista de su microrrelato "El escritor en tiempos de crisis", la mujer escritora "que dice no" lo hace mediante el uso de "la palabra con vocación de testigo" (Otxoa, 2006: 108); una palabra cargada de mirada y de memoria.

\footnotetext{
${ }^{15} \mathrm{Al}$ publicarse, con posterioridad, el texto de la conferencia en que la autora apuntó esta idea, Otxoa reformuló la imagen, y las "carreteras" pasaron a ser "caminos" (2019: 27).
} 


\section{REFERENCIAS BIBLIOGRÁFICAS}

ANDRÉS-SuÁREZ, I. (2018). "Esperpento redivivo en la obra de Julia Otxoa". En El microrrelato en la España plurilingüe, I. Andres-Suárez (ed.), 189-203. Valladolid: Universidad de Valladolid.

BenEgas, N. y MunÁRRIZ, J., EDS. (1997). Ellas tienen la palabra. Dos décadas de poesía española. Madrid: Hiperión.

CARrillo Martín, N. (2012). "El enigma como punto de partida y de llegada: Los microrrelatos de Julia Otxoa". En En breve: Cuentos de escritoras españolas (1975-2010). Estudios y antología, Á. Encinar y C. Valcárcel (eds.), 91-104. Madrid: Biblioteca Nueva.

EnAmorado, V. (2014). "Voces. Entrevista. Julia Otxoa: en el continuum de la creación. Entrevista a Julia Otxoa". Contrapunto. Publicación de Crítica e Información Literaria 12 (mayo), 32-36.

ENCINAR, Á. (2012). "La lógica del absurdo: Un extraño envío de Julia Otxoa". En En breve: Cuentos de escritoras españolas (1975-2010). Estudios y antología, Á. Encinar y C. Valcárcel (eds.), 123-139. Madrid: Biblioteca Nueva. (2013): "Paisajes hilvanados". En Escena de familia con fantasma, J. Otxoa, 7-11. Palencia: Menoscuarto.

MARTín Gaite, C. (1983). El cuento de nunca acabar. Madrid: Triestre.

Moyano, A. (2008). "Entrevista a Julia Otxoa”. El Diario Vasco, 23 de julio. Disponible en línea: https://www.diariovasco.com/20080723/cultura/escritor-debe-estarcosido-20080723.html [10/11/2020].

ОтхоА, J. (2000). Al calor de un lápiz. Zarautz: Ikeritz.

(2006). Un extraño envío (Relatos breves). Palencia: Menoscuarto.

(2011). La nieve en los manzanos. Nueva York: Digitalia Hispánica.

(2013). Escena de familia con fantasma. Palencia: Menoscuarto.

(2014). Jardín de arena. Madrid: Ediciones La Palma.

(2017). "La perplejidad ante el mundo. Alegorías del laberinto". Conferencia plenaria (18 de octubre) en el II Congreso Internacional Figuraciones de lo insólito en las literaturas españolas e hispanoamericana (siglos XX-XXI). León: Universidad de León.

(2018). Confesiones de una mosca. Palencia: Menoscuarto.

(2019): "El poder de la imaginación. La alegoría como salida al laberinto". En Realidades fracturadas. Estéticas de lo insólito en la narrativa en lengua española (1980-2018), N. Álvarez Méndez y A. Abello Verano (eds.), 23-27. Madrid: Visor Libros.

Pérez Bustamante, A. S. (2009). "Un león en la cocina. Los microrrelatos de Julia Otxoa". En Narrativas de la posmodernidad. Del cuento al microrrelato, S. Montesa (ed.), 279-296. Málaga: AEDILE. 
RoAs, D. (2011). Tras los límites de lo real. Una definición de lo fantástico. Madrid: Páginas de Espuma.

RÓDENAS DE MOYA, D. (2008). "Contar callando y otras leyes del microrrelato". Ínsula. Revista de Letras y Ciencias Humanas 741 [Monográfico sobre El microrrelato en España: tradición y presente, F. Valls (coord.)], 6-9.

Rosal, M. (2006). Con voz propia. Estudio y antología comentada de la poesía escrita por mujeres (1970-2005). Sevilla: Renacimiento.

SALA, T. (2002). "Entrevista a Julia Otxoa". Euskonews \& Media, 12-19 de julio. Disponible en línea: http://www.euskonews.eus/0175zbk/elkar17501es.html [18/11/2020].

Fecha de recepción: 27/11/2020

Fecha de aceptación: 17/03/2021 